\title{
Secondary antibody deficiency - causes and approach to diagnosis
}

\author{
Authors: Sapna Srivastava ${ }^{A}$ and Philip Wood ${ }^{A}$
}

Antibody deficiencies can occur in the context of primary disorders due to inherited genetic defects; however, secondary immune disorders are far more prevalent and can be caused by various diseases and their treatment, certain medications and surgical procedures. Immunoglobulin replacement therapy has been shown to be effective in reducing infections, morbidity and mortality in primary antibody deficiencies but secondary antibody deficiencies are in general poorly defined and there are no guidelines for the management of patients with this condition. Clinical decisions are based on experience from primary antibody deficiencies. Both primary and secondary antibody deficiencies can be associated with infections, immune dysregulation and end-organ damage, causing significant morbidity and mortality. Therefore, it is important to diagnose and treat these patients promptly to minimise adverse effects and improve quality of life. We focus on secondary antibody deficiency and describe the causes, diagnosis and treatment of this disorder.

\section{Definition and causes}

Antibody deficiency is defined quantitatively by an immunoglobulin (IgG) level significantly below the normal range or a failure of immunoglobulin function (hypogammaglobulinaemia). Primary antibody deficiencies are caused by genetic defects that usually affect B-cell development and/or function. ${ }^{1}$ The majority of these are likely to have a polygenic aetiology. Hypogammaglobulinaemia can also be due to conditions that result in immunoglobulin loss or affect B-cell numbers and/or function. Causes of secondary antibody deficiencies include protein losing states - such as nephrotic syndrome - and protein-losing enteropathy, hematologic malignancies, chemotherapy, solid-organ transplantation, infectious diseases and the adverse effects of specific therapeutic drugs (Table 1)..$^{2,3}$

The clinical significance of this condition is the risk of life-threatening infections by encapsulated organisms, such as streptococcus and Haemophilus influenzae (normally dealt with by antibody responses), which makes it crucial that

Authors: ${ }^{\text {A }}$ consultant clinical immunologist, Department of Clinical Immunology and Allergy, St James's University Hospital, Leeds, UK. patients who could be potentially affected are fully assessed and monitored for antibody deficiency and prophylactic measures, such as antibiotics or immunoglobulin replacement therapy (IgRT), are promptly instituted to prevent end organ damage. Not all forms of secondary hypogammaglobulinaemia are thought to confer an increased risk of infections, but this has not been well studied for the majority of conditions. ${ }^{2}$

\section{Medications}

There are many classes of drugs that can cause antibody deficiency and, therefore, a complete drug history is mandatory. Both long- and short-term systemic treatment with corticosteroids have been associated with decreased immunoglobulin levels but not increased infection rates. ${ }^{4}$

\section{Key points}

Secondary antibody deficiency is most commonly caused by lymphoproliferative disorders and drugs

These patients have an increased risk of infection, which may be life-threatening because of quantitative and qualitative defects in the humoral immune response

A full immunological work-up, including measurement of specific antibody responses, IgG subclasses and frequency of infections, is required to assess potential susceptibility to infections in hypogammaglobulinaemic patients

In patients with low immunoglobulin levels, vaccination response to the pneumococcal polysaccharide vaccine should be checked to give an indication regarding immune function, even if the patient has not suffered with infections, as they may be at risk of severe sepsis

There are no clear guidelines for the management of secondary antibody deficiency.

KEYWORDS: antibody deficiency, immunodeficiency, immunoglobulin replacement, malignancy, secondary hypogammaglobulinaemia 


$\begin{aligned} & \text { Table 1. Conditions causing secondary antibody } \\ & \text { deficiency }\end{aligned}$
$\begin{array}{ll}\text { Malignancy } & \text { Chronic lymphocytic leukaemia } \\ & \text { Multiple myeloma } \\ & \text { Good's syndrome } \\ & \text { Non-Hodgkin lymphoma } \\ \text { Immunoglobulin loss } & \text { Protein losing enteropathy } \\ & \text { Nephrotic syndrome } \\ & \text { Plasma exchange } \\ & \text { Severe dermatitis } \\ \text { Drugs } & \text { Phenytoin, carbamazepine, } \\ \text { Anticonvulsants } & \text { valproate, lamotrigine } \\ \text { Long-term or frequent } \\ \text { corticosteroids Gold, } \\ \text { penicillamine, sulfasalazine } \\ \text { cyclophosphamide, } \\ \text { azathioprine mycophenolate } \\ \text { (in allogeneic and solid organ } \\ \text { transplantation) } \\ \text { Rituximab } \\ \text { Belimumab } \\ \text { Epstein-Barr virus, } \\ \text { cytomegalovirus, HIV, parvovirus } \\ \text { B19, congenital rubella }\end{array}$
Anti-B-cell antibodies

Patients with asthma and hypogammaglobulinaemia secondary to corticosteroid use retain specific antibody responses and, thus, are not necessarily candidates for IgRT. Patients who take daily doses of $\geq 12.5 \mathrm{mg}$ prednisone for 1 year or more are more likely to have hypogammaglobulinaemia and IgG levels are inversely correlated with corticosteroid dose. ${ }^{4}$

Immunosuppressants combined with corticosteroids may create an even greater propensity toward hypogammaglobulinaemia. Biological drugs can cause secondary hypogammaglobulinaemia and this should be borne in mind when commencing these drugs (Fig 1, Table 2). Such treatments are commonly used in patients with autoimmune and neoplastic diseases. An example is rituximab, which is an anti-CD20 monoclonal antibody. Rituximab may cause hypogammaglobulinaemia, particularly if given in multiple cycles and in those patients with lower antibody levels pretreatment. It is particularly associated with infections when combined with other chemotherapeutic agents. ${ }^{4}$ Rituximab targets peripheral B-cells and can deplete them for several months. Although usually transient, hypogammaglobulinaemia can be persistent and clinically significant, requiring intravenous immunoglobulin therapy to control infections. ${ }^{5}$ Rituximab illustrates the point that transient or permanent derangement of humoral immune function can be caused by biological treatment; vigilance for this is essential.

Periodic monitoring after rituximab therapy for recovery of B-cell numbers, serum immunoglobulins and vaccine responses may help identify patients that develop persistent hypogammaglobulinaemia and would benefit from IgRT before they have significant infections. Rituximab-induced

Table 2. Biological drugs causing secondary hypogammaglobulinaemia

\begin{tabular}{|c|c|c|c|}
\hline Mechanism of action & Target & Drug & Use \\
\hline \multirow[t]{7}{*}{ B-cell depleting } & \multirow[t]{5}{*}{ Anti-CD20 } & Rituximab & \multirow{5}{*}{$\begin{array}{l}\text { Haematological B-cell malignancies, lupus } \\
\text { nephritis, ANCA-associated vasculitis }\end{array}$} \\
\hline & & Ocrelizumab & \\
\hline & & Ofatumumab & \\
\hline & & Veltuzumab & \\
\hline & & Obinutuzumab & \\
\hline & Anti-CD52 & Alemtuzumab & $\begin{array}{l}\text { Chronic lumphocytic leukaemia, multiple } \\
\text { sclerosis, T-cell lymphoma, conditioning } \\
\text { regimen for transplant }\end{array}$ \\
\hline & Anti-CD74 & Milatuzumab & $\begin{array}{l}\text { Non-Hodgkin lymphoma, chronic } \\
\text { lymphocytic leukaemia, multipke myeloma }\end{array}$ \\
\hline \multirow[t]{3}{*}{ Inhibiting B-cell survival } & \multirow[t]{3}{*}{ Anti-BAFF } & Belimumab & \multirow{3}{*}{$\begin{array}{l}\text { Clinical trials for autoimmune disease and } \\
\text { haematological malignancies }\end{array}$} \\
\hline & & Tabalumab & \\
\hline & & Atacicept (also antagonises effect of APRIL) & \\
\hline \multirow[t]{4}{*}{ Inhibiting B-cell activation } & Anti-CD22 & Epratuzumab & \\
\hline & $\begin{array}{l}\text { Proteosome } \\
\text { inhibition }\end{array}$ & Bortezomib & Multiple myeloma, mantle cell lymphoma \\
\hline & \multirow[t]{2}{*}{ Anti-TKI } & Imatinib & \multirow{2}{*}{$\begin{array}{l}\text { Chronic myelogenous leukaemia, gastric } \\
\text { stromal tumour }\end{array}$} \\
\hline & & Dasatinib & \\
\hline Inhibiting T-cell/B-cell interaction & Anti-CD80/86 & Abatacept & Rheumatoid arthritis \\
\hline
\end{tabular}




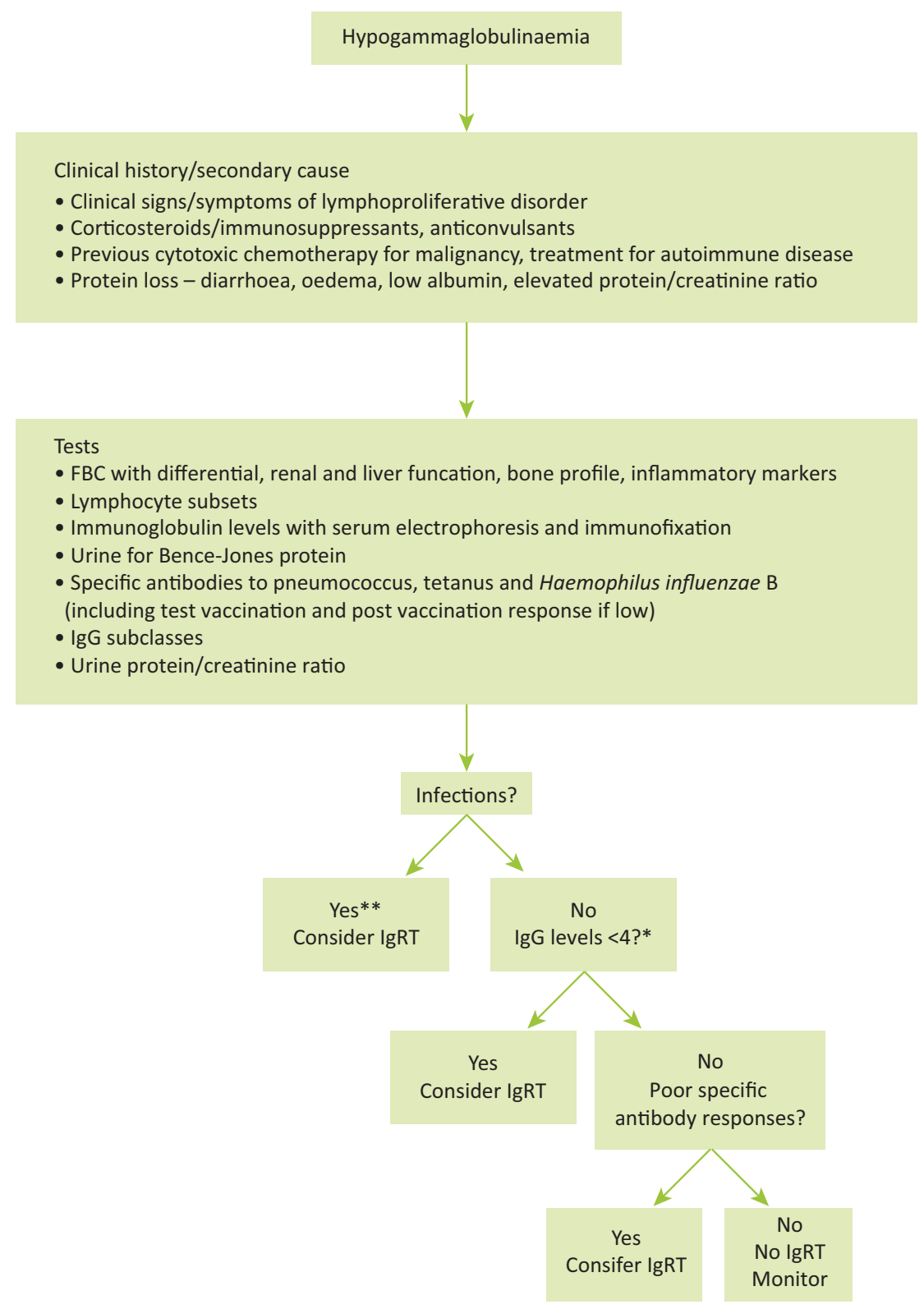

Fig 1. Investigation and management of secondary antibody deficiency. *Patients with secondary antibody deficiencies may have a normal IgG level but poor specific antibody responses making them susceptible to infections; immunoglobulin replacement therapy should be considered. ${ }^{* *}$ Consider a trial of prophylactic antibiotics before resorting to immunoglobulin therapy. $\mathrm{FBC}$ = full blood count; IgG = immunoglobulin G; IgRT = immunoglobulin replacement therapy hypogammaglobulinaemia may persist for a prolonged period of at least 2 years, likely because of the different mechanisms involved. ${ }^{6}$ It is currently unclear whether antibody levels ever recover in some patients after chemotherapy treatments such as rituximab.

Gold, penicillamine and sulfasalazine have been implicated in varying degrees of hypogammaglobulinaemia. ${ }^{7}$ A number of anticonvulsants, such as phenytoin, carbamazepine and lamotrigine, may cause reversible hypogammaglobulinaemia particularly IgA deficiency. ${ }^{8}$ For all these drugs, clinically significant hypogammaglobulinaemia is rare although symptomatic panhypogammaglobulinaemia has been noted in a small number of cases requiring IgRT to prevent recurrent infections. Symptoms and immunoglobulin levels tend to normalise within several months of treatment cessation. $^{8}$

\section{Malignancies}

Malignancies, especially lymphoproliferative disorders (chronic lymphocytic leukaemia (CLL) ${ }^{9}$ and myeloma), are commonly associated with hypogammaglobulinaemia. This may be due to the malignancy itself or treatment of the condition.

Patients with CLL have a high incidence of infective complications. ${ }^{10}$ The associated hypogammaglobulinaemia is due to abnormal clones of B-lymphocytes inhibiting the function of normal B-cells and can be found in up to $70 \%$ of patients, correlating with stage and duration of disease and often persisting despite disease remission. ${ }^{11}$ However, only a subset of these patients are susceptible to infections. Patients with CLL do not mount adequate responses to vaccination. Infection risk is likely to be highest in those with associated IgG subclass deficiency and poor specific antibody responses. 


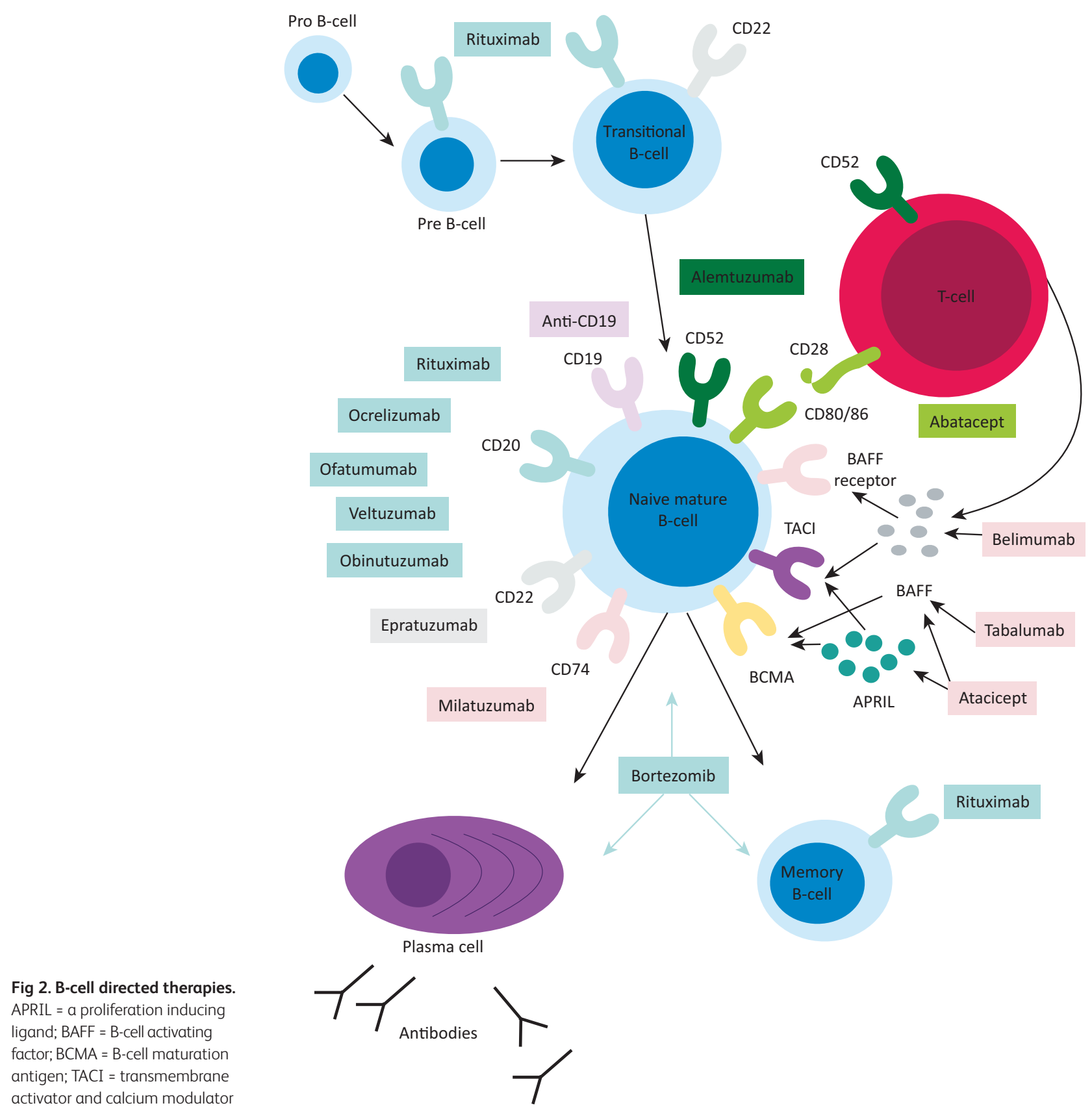

Treatment of CLL usually makes the immunodeficiency worse. Several clinical trials have demonstrated a reduction in the incidence of mild to moderate bacterial infections from the use of prophylactic IgRT but none have shown a decrease in mortality. ${ }^{11}$ In order to improve cost effectiveness, confining treatment to patients whose serum IgG is less than $500 \mathrm{mg} / \mathrm{dL}$ and who are suffering with severe or recurrent infections has been suggested. ${ }^{11}$

Chemotherapeutic agents may also cause associated deficiencies in cell mediated immunity and cause neutropenia as well as antibody deficiency, resulting in an increased infection risk. ${ }^{12}$ These must be diagnosed and appropriate prophylactic treatment (eg co-trimoxazole for CD4 T-cell lymphopenia) instituted.

Multiple myeloma is a plasma cell malignancy where clones of plasma cells are dysregulated and produce monoclonal immunoglobulin with little functional antibody. Chemotherapy can exacerbate this and IgRT has been used successfully to decrease bacterial infections. ${ }^{13}$

Hypogammaglobulinaemia can also be associated with thymoma in Good's syndrome. The antibody deficiency is usually symptomatic and associated with a defect in cellular immunity, predisposing the patient to opportunistic as well as encapsulated bacterial infections. Despite thymectomy, 
hypogammaglobulinaemia persists and has been found to respond well to IgRT. ${ }^{14}$

\section{Immunoglobulin loss}

Conditions causing protein loss through the gastrointestinal tract, such as protein-losing enteropathy, or through the renal tract, such as nephrotic syndrome, can also cause hypogammaglobulinaemia and increase the risk of bacterial infections. ${ }^{15}$ These diseases are distinguished from primary humoral immunodeficiency by the presence of oedema and decreased serum albumin. Treatment with immunosuppressive drugs, such as glucocorticoids, further increases the risk of infection.

Protein-losing enteropathies include coeliac disease, inflammatory bowel disease and intestinal lymphangiectasia. Protein loss should be demonstrable by measurement of the alpha-1 antitrypsin clearance in the stool.

Intestinal lymphangiectasia is caused by blockage of interstitial lymphatics with resultant leakage of lymphatic fluid, immunoglobulins and lymphocytes into the gastrointestinal tract lumen. ${ }^{16}$ It may occur as a result of surgery for congenital heart disease (Fontan procedure) ${ }^{17}$ Hypogammaglobulinaemia secondary to protein loss can also be caused by peritoneal dialysis and severe burns. These disorders are treated by managing the underlying condition as there is scarce data regarding the efficacy of IgRT. It is generally believed that patients with hypogammaglobulinaemia caused by protein loss have antibodies of good quality because of the preservation of antibody responses and would therefore be less susceptible to infection. ${ }^{18}$

\section{Infections}

Transiently reduced antibody responses have been identified following uncomplicated Epstein-Barr virus infection and congenital rubella. ${ }^{14}$ Antibody deficiencies have also been described as a result of cytomegalovirus, measles, parvovirus B19 and congenital Toxoplasma gondii infection. ${ }^{19}$

HIV patients tend to exhibit hypergammaglobulinaemia but specific antibody responses to encapsulated bacteria can be inadequate because of the T-cell defect. There can also be associated IgG subclass deficiencies, resulting in susceptibility to infections. ${ }^{20}$

\section{Patient assessment and management}

A complete full blood count with differential and immunoglobulin levels should be taken and specific antibody levels to pneumococcus, Haemophilus influenzae and tetanus should be tested for.

Two main strategies are indicated for patients with hypogammaglobulinaemia who develop recurrent bacterial infections: antibiotic prophylaxis and IgRT.

Immunoglobulin has been widely used in primary antibody deficiencies patients as it reduces the risk of infections. ${ }^{21}$ However, there are no clear indications regarding the use of prophylactic IgRT in secondary antibody deficiencies despite the broad range of disorders associated with clinically significant hypogammaglobulinaemia. ${ }^{22}$ Bacterial infection, in particular, is a major cause of morbidity and mortality for patients with lymphoma, multiple myeloma, connective tissue disorders or for those taking immunosuppressive drugs or corticosteroids. ${ }^{4,10,11,23}$

Antibody deficiency can manifest as hypogammaglobulinaemia or by subtler subclass or functional antibody deficiencies in the presence of a normal total IgG. There is commonly a delay in diagnosis and management. Secondary antibody deficient patients may appear asymptomatic despite significant levels of hypogammaglobulinaemia but will be at risk of serious, potentially life-threatening infections. Better awareness and monitoring of patients at risk could help identify these patients before they develop infections. Screening methods would include annual measurement of IgG, IgA and IgM levels and humoral immune function should be assessed by measuring specific antibodies to pneumococcal capsular polysaccharides. If antibody titres are low, patients should be vaccinated with the unconjugated polyvalent pneumococcal vaccine (Pneumovax II) if they have not received this in the previous 5 years. Blood should be tested again for pneumococcal antibodies 4 weeks after vaccination to check the patient's response. For subjects aged 6-65 years, a normal response has been defined as protective antibodies to $70 \%$ of the serotypes tested, with at least a twofold increase in the titres. ${ }^{24}$ A good antibody response after vaccination suggests reasonable immune function. Conversely, poor antibody response alerts the clinician to the possibility of increased infection susceptibility. Checking anti-tetanus and Haemophilus antibody titres can also show immune responses to previous vaccinations.

Prophylactic antibiotics, such as macrolides (eg azithromycin $500 \mathrm{mg}$ three times per week), may be effective but their use is not evidence based. There should be a low threshold to consider IgRT, particularly when antibody deficiency is associated with poor specific antibody responses. Initiating screening and treatment of infections earlier and prescribing prolonged antibiotic courses (eg a 2-week course of co-amoxiclav $625 \mathrm{mg}$ three times daily for an uncomplicated respiratory tract infection) is recommended as prevention of infection reduces end organ damage and mortality.

\section{Conflicts of interest}

The authors have no conflicts of interest to declare.

\section{References}

1 Duraisingham SS, Buckland MS, Grigoriadou S et al. Secondary antibody deficiency. Expert Rev Clin Immunol 2014;10:583-91.

2 Ochs H D, Stiehm ER, Winkelstein JA et al. Antibody deficiencies. In: Stiehm ER, Ochs HD, Winkelstein JA (eds). Immunologic disorders in infants and children, 5th edn. Philadelphia, PA: Saunders, 2004:356-426.

3 Onigbanjo MT, Orange JS, Perez EE, Sullivan KE. Hypogammaglobulinemia in a pediatric tertiary care setting. Clin Immunol 2007;125:52-9.

4 Kawano T, Matsuse H, Obase Y et al. Hypogammaglobulinemia in steroid-dependent asthmatics correlates with the daily dose of oral prednisolone. Int Arch Allergy Immunol 2002;128:240-3.

5 Casulo C, Maraguila J, Zelenetz AD. Incidence of hypogammaglobulinaemia in patients receiving rituximab and the use of intravenous immunoglobulin for recurrent infections. Clin Lymphoma Myeloma Leuk 2013;13:106-11. 
6 Shortt J, Spencer A. Adjuvant rituximab causes prolonged hypogammaglobulinaemia following autologous stem cell transplant for nonHodgkin's lymphoma. Bone Marrow Transplant 2006;38:433-6.

7 Lee AH, Gevinson AI, Jr Schumacher HR. Hypogammaglobulinaemia and rheumatic disease. Semi Arthritis Rheum 1993;22:252.

8 Castro AP, Redmershi MG, Pastoring AC et al. Secondary hypogammaglobulinaemia after use of carbamazepine: case report and review. Rev Hosp Clin Fac Med Sao Paulo 2001;56:189-92.

9 Dhalla F, Lucas M, Schuh A et al. Antibody deficiency secondary to chronic lymphocytic leukemia: should patients be treated with prophylactic replacement immunoglobulin? J Clin Immunol 2014;34:277-82.

10 Morrison VA. Infectious complications of chronic lymphocytic leukaemia: pathogenesis, spectrum of infection, preventive approaches. Best Pract Res Clin Haematol 2010;23:145-53.

11 Raanani P, Gafter-Gvili A, Paul M et al. Immunoglobulin prophylaxis in chronic lymphocytic leukemia and multiple myeloma: systematic review and meta-analysis. Leuk Lymphoma 2009;50:764-72.

12 Tsiodras S, Samonis G, Keating MJ, Kontoyiannis DP. Infection and immunity in chronic lymphocytic leukemia. Mayo Clin Proc 2000;75:1039-54.

13 Snowden JA, Ahmedzai SH, Ashcroft J et al. Guidelines for supportive care in multiple myeloma 2011. Br J Haematol 2011;154:76-103.

14 Wang $\mathrm{CH}$, Chan ED, Perng CL et al. Intravenous immunoglobulin replacement therapy to prevent pulmonary infection in a patient with Good's syndrome. J Microbiol Immunol Infect 2015;48:229-32.

15 Ogi M, Yokoyama H, Tomosugi N et al. Risk factors for infection and immunoglobulin replacement therapy in adult nephrotic syndrome. Am J Kidney Dis 1994;24:427-36.

16 Fuss IJ, Strober W, Cuccherini BA et al. Intestinal lymphangiectasia, a disease characterized by selective loss of naive CD45RA+ lymphocytes into the gastrointestinal tract. Eur J Immunol 1998;28:4275-85.
17 Ostrow AM, Freeze H, Rychik J. Protein-losing enteropathy after fontan operation: investigations into possible pathophysiologic mechanisms. Ann Thorac Surg 2006;82:695-700.

18 Buckley RH, Wff RI. The use of intravenous immune globulin in immunodeficiency disease. N Engl J Med 1991;325:110-7.

19 Herriot R, Sewell WA. Antibody deficiency. J Clin Pathol 2008;61:994-1000.

20 Crum-Cianflone NF, Collins G, Defang G et al Immunoglobulin $\mathrm{G}$ subclass levels and antibody responses to the 2009 influenza A (H1N1) monovalent vaccine among human immunodeficiency virus (HIV)- infected and HIV-uninfected adults. Clin Exp Immunol 2012;168:135-41.

21 Bonilla FA, Khan DA, Ballas ZK et al. Practice parameter for the diagnosis and management of primary immunodeficiency. J Allergy Clin Immunol 2015;136:1186.

22 Department of Health. Clinical guidelines for immunoglobulin use, 2nd edn. London: DoH, 2008.

23 Cervera R, Khamashta MA, Font J et al. Morbidity and mortality in systemic lupus erythematosus during a 10-year period: a comparison of early and late manifestations in a cohort of 1,000 patients. Medicine 2003;82:299-308.

24 Orange JS, Ballow M, Stiehm ER et al. Use and interpretation of diagnostic vaccination in primary immunodeficiency: a working group report of the Basic and Clinical Immunology Interest Section of the American Academy of Allergy, Asthma \& Immunology. J Allergy Clin Immunol 2012;130(Suppl 3):S1-24.

Address for correspondence: Dr P Wood, Department of Clincial Immunology and Allergy, St James's University Hospital, Leeds Teaching Hospitals NHS Trust, Beckett Street, Leeds LS9 7TF, UK.

Email: Philipwood1@nhs.net

\title{
Immunoglobulin therapy
}

\author{
Authors: Sarah Louise Johnston ${ }^{A}$ and Rob Hollingsworth ${ }^{B}$
}

Immunoglobulin is an expensive blood product of potentially limited supply used in a wide variety of medical conditions, across a number of specialties. Historically, immunoglobulin has been associated with transmission of blood borne infection (eg hepatitis C). Immunoglobulin use needs to be carefully considered, appropriately prescribed and recorded. The Department of Health, in conjunction with relevant stakeholders, has established a demand management programme to secure immunoglobulin supplies for patients most in need of treatment and to limit use for indications where evidence is lacking.

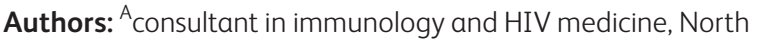
Bristol NHS Trust, Bristol, UK; ${ }^{\text {B }}$ managing director, Medical Data Solutions and Services, Manchester UK

\section{Introduction}

Immunoglobulin is a blood product, centrally funded by NHS England and used in a wide variety of medical conditions, across a number of different specialties. The aim of this short review is to provide some background into immunoglobulin use, highlight specific issues associated with immunoglobulin therapy and outline the Department of Health's Demand Management Programme.

Immunoglobulin is derived from pooled blood donation. It predominantly consists of $\operatorname{IgG}$, with minimal amounts of IgA and IgM. Broadly, immunoglobulin use can be divided by indication into replacement therapy - for patients with primary and secondary immune deficiency diseases - and immunomodulatory therapy, for treatment of a number of autoimmune and inflammatory conditions. 